\title{
Odontogenic Keratocyst Tumor: A Case Report and Literature Review
}

\author{
Akram Belmehdi ${ }^{1}$, Saliha Chbicheb ${ }^{2}$, Wafaa El Wady ${ }^{2}$ \\ ${ }^{1}$ Department of Oral Surgery, Dental Center of Treatment and Diagnosis (Ibn Sina Hospital), \\ Rabat, Morocco \\ ${ }^{2}$ Oral Surgery Service, Faculty of Dentistry of Rabat, Mohammed V University, Rabat, Morocco \\ Email: akram.belmehdi@gmail.com, s_chbicheb@yahoo.fr, w.elwady@um5s.net.ma
}

Received 17 February 2016; accepted 11 July 2016; published 14 July 2016

Copyright (C) 2016 by authors and Scientific Research Publishing Inc.

This work is licensed under the Creative Commons Attribution International License (CC BY).

http://creativecommons.org/licenses/by/4.0/

(c) (i) Open Access

\section{Abstract}

First described by Philipsen in 1956, the odontogenic keratocyst is characterized by a large squamous keratinization of its border, an aggressive growth and a high recurrent rate. It is now designated by the World Health Organization as a keratocystic odontogenic tumour (KOT). Clinically, the KOT is manifested by an asymptomatic growth. Radiographically, it appears as a well-defined unilocular or multilocular osteolytic lesion. The diagnostic approach is based on a combined analysis of the medical history, the clinical appearance and the radiographic appearance. The diagnosis may be confirmed by the anatomical pathology report. Finally, treatment consists of surgical excision and follow up is characterized by a high rate of recurrence. The authors report a case of keratocystic odontogenic tumor of the upper jaw and review the various diagnoses, therapeutics and follow up aspects of this type of tumors.

\section{Keywords}

Keratocystic Odontogenic Tumor, Benign Tumor, Surgery, Maxilla

\section{Introduction}

Odontogenic keratocyst (OKC) was a neoplasm described by Philipsen in 1956 [1] and was confirmed by Browne in 1970 and 1971 [2] [3]. At that time, it was believed to be a benign, but potentially aggressive and recurrent, odontogenic cyst, and probably represented the lesion previously termed a primordial cyst [4] [5].

The diagnostic metamorphosis of OKC into a recognized cystic neoplasm occurred after observation of its biological behaviors and modern investigations of chromosomal and genetic abnormalities consistent with neoplastic progression [6] [7]. In 2005 [8], the WHO Working Group considered odontogenic keratocyst (OKC) to 
be a tumor, recommended the term keratocystic odontogenic tumor (KCOT), separating the lesion from the orthokeratinizing variant, which was now considered an odontogenic cyst [9].

In this paper, we shall present one case report of a keratocyst, which derived from an impacted canine. In addition, we review the treatment of odontogenic keratocyst, and briefly discuss novel trends that help to make diagnosis and therapy more specific and effective.

\section{Case Report}

A 28-year old man was referred to the Department of Oral Surgery complaining of painless swelling in the right side of upper jaw. The patient's medical history revealed that he had been having these complaints for one year.

The patient's medical story was unremarkable, and the interrogation reports no previous history of extraction or previous infectious episode.

An extraoral examination revealed slight swelling and tenderness over the right cheek with an induration of the nasal region while the integuments are normal.

Intraoral examination showed missing right canine with mild tenderness on palpation. There was no evidence of vestibular obliteration, expansion or pus discharge (Figure 1).

Besides, the rest of the intraoral examinations showed a poor oral-dental hygiene with presence of calculus blocks, especially in the lower anterior sector, generalized gingivitis.

Orthopantomogram showed a vast unilocular radiolucent body, with clear contours within the maxillary bone and inserting itself in the collar of the impacted canine, extending transversely from the tooth 23 to the distal root of the tooth 17 (Figure 2).

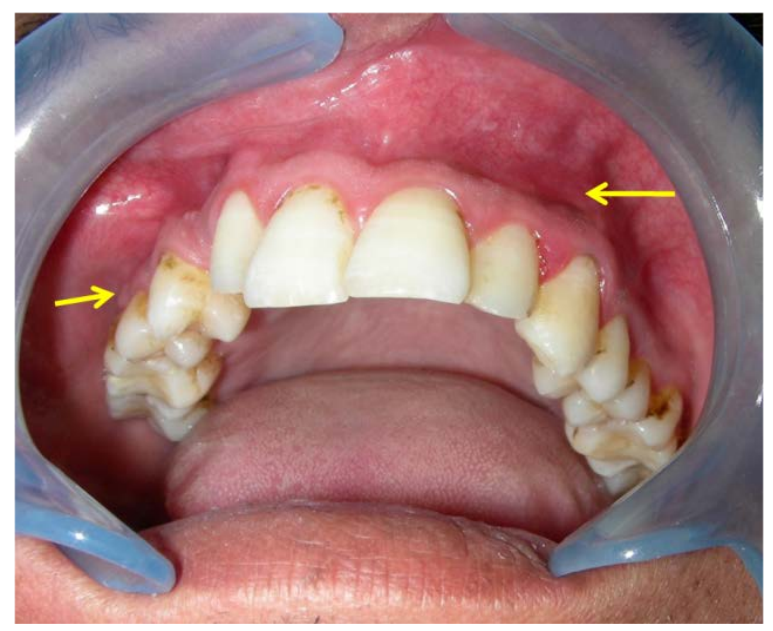

Figure 1. Intraoral view.

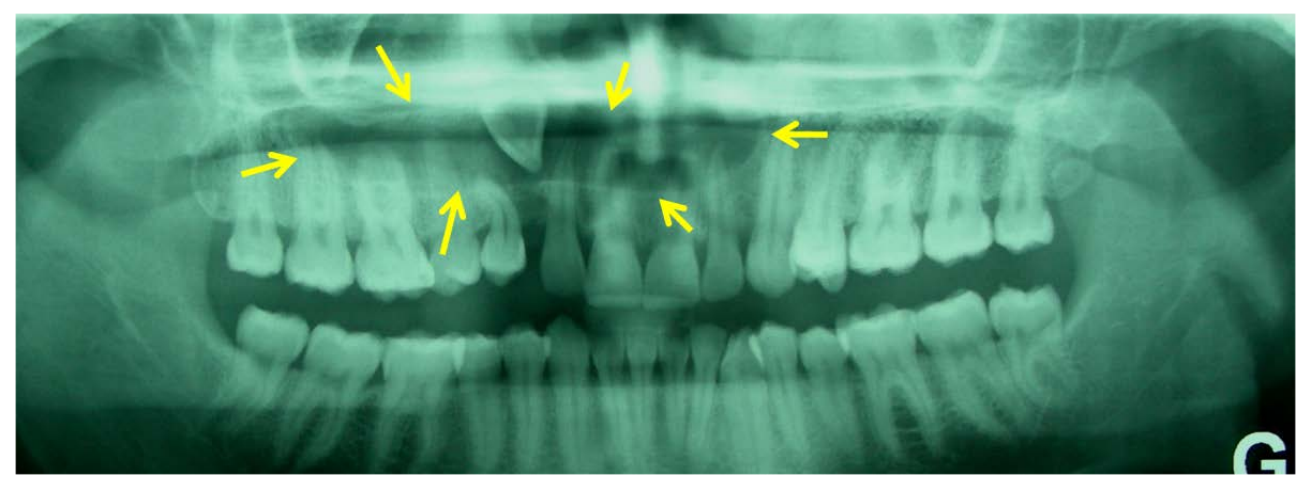

Figure 2. Orthopantomogram showed a vast unilocular radiolucent body, with clear contours within the maxillary bone. 
Coronal sections of CT scan had shown a slight fragility of the floor of the nasal cavity of the left side and integrity of the maxillary sinus (Figure 3(a) and Figure 3(b)), while axial sections revealed a greater extent anteroposteriorly than buccopalatly (Figure 3(c)).

According to these clinical and radiological features, different diagnosis can be evoked notably:

- Keratocyst;

- Dentigerous cyst due to the presence of the radiolucency containing the tooth crown;

- Adenomatoid odontogenic tumor, because of a radiolucency containing an impacted tooth in association;

- Ameloblastoma, due to a unicystic image in relation with an impacted tooth.

Irrespective of the evoked diagnosis, the treatment objective is a surgical removal. Therefore, an intervention under a local anaesthesia was decided, and the lesion was entirely enucleated (Figure 4).

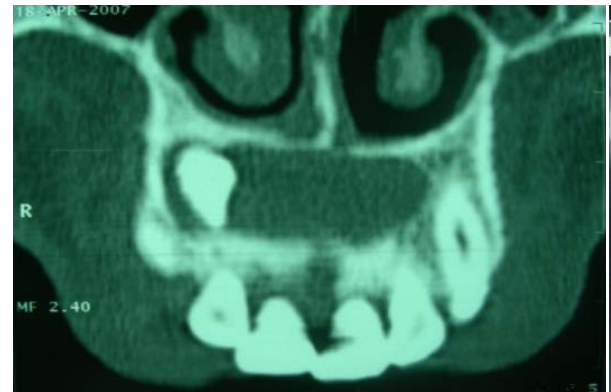

(a)

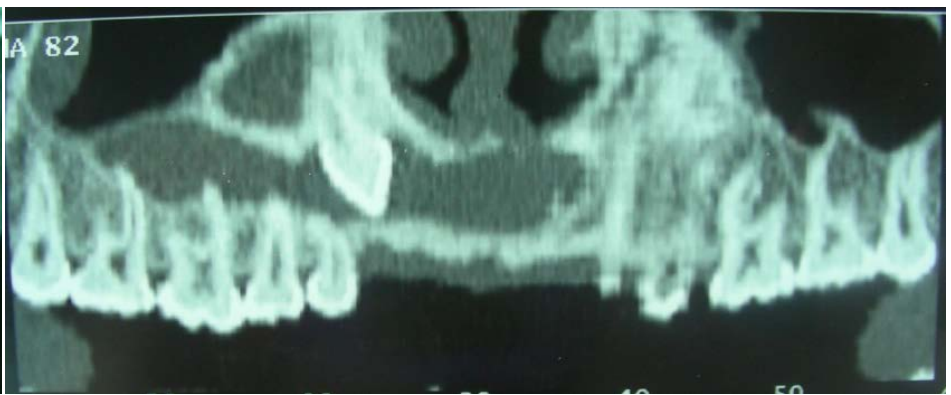

(b)

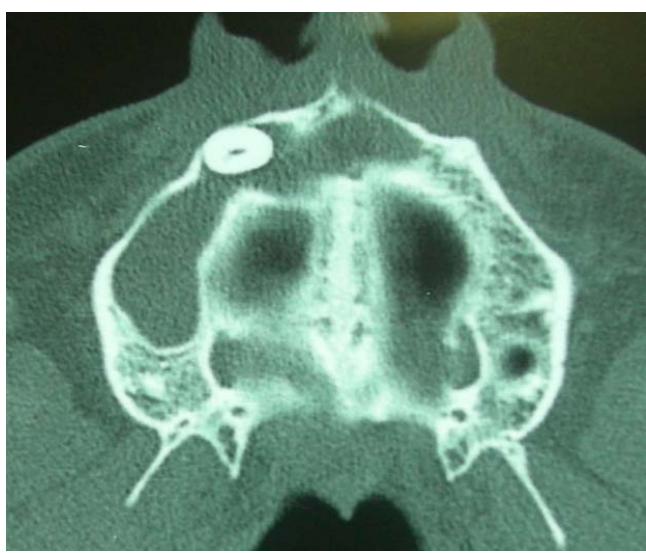

(c)

Figure 3. (a) (b) Coronal sections of CT scan: a slight fragility of the floor of the nasal cavity of the left side and integrity of the maxillary sinus; (c) Axial sections revealed a greater extent anteroposteriorly than buccopalatly.

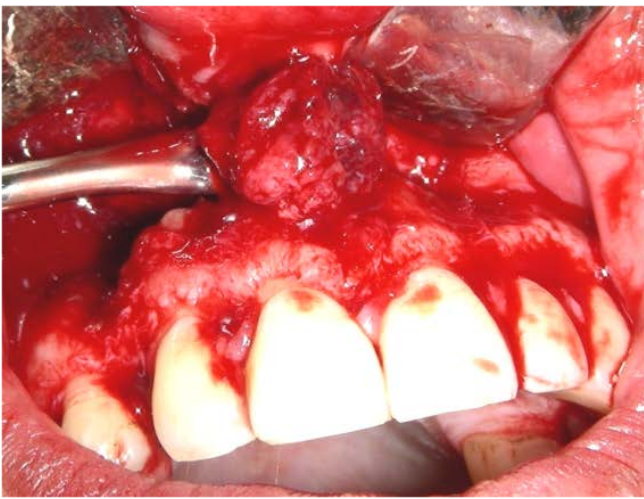

(a)

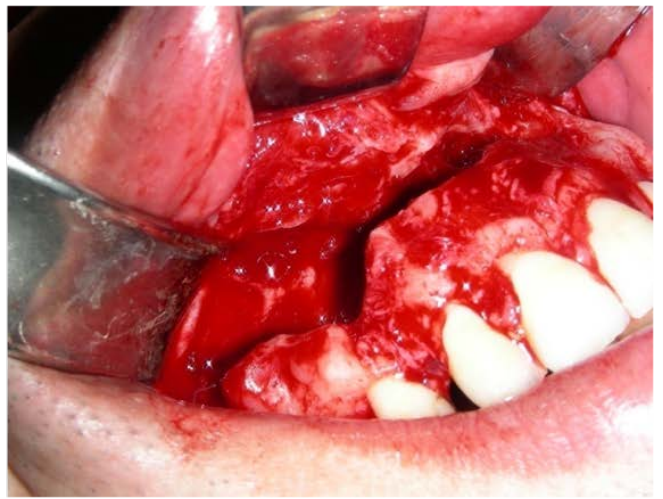

(b)

Figure 4. Intraoral view. (a) Enucleation of the lesion; (b) Bone cavity after enucleation. 
The removed tissue of $6 \mathrm{~cm}$ in anteriorposterior dimension and $1 \mathrm{~cm}$ in vertical dimension, fixed in $10 \%$ buffered formalin, is sent for an anatomopathological study (Figure 5).

The histological examination has showen a cyst wall lined by stratified squamous epithelium and the corrugated parakeratinized surface. The epithelial lining is supported by a chronically inflamed connective tissue (Figure 6).

Upon this examination, the lesion is concluded to be keratocyst odontogenic tumor.

Concerning the follow-up, there was no sign of recurrence after 2 years postoperatively.

\section{Discussion}

The odontogenic keratocyst is a histopathologically and behaviorally unique, specific entity. It is the most agressive and recurrent of all the odontogenic cysts and shows characteristics resembling both a cyst and a benign tumor [10].

This term was subsequently replaced in the 2005 edition of the World Health Organization Classification of the Head and Neck Tumors, by the term "keratocystic odontogenic tumor" (KCOT). The World Health Organization working group believed that this new term truly reflected the neoplastic nature of this lesion. This reclassification was determined by the clinical features of this tumor, including its potential for locally destructive behavior, high recurrence rate, and tendency to multiplicity [10] [11].

Most odontogenic keratocyst (60\%) arise from dental lamina rests or from the basal cells of oral epithelium and are thus primordial-origin odontogenic keratocysts (Figure 7(a)) [10]. The remaining 40\% arise from the reduced enamel epithelium of the dental follicle and are thus dentigerous-origin odontogenic keratocysts (Figure 7(b)) as we have seen in our case report [10]. This clinical identification is of some importance because recurrences are more frequently seen after treatment of the primordial-origin type [5] [10].

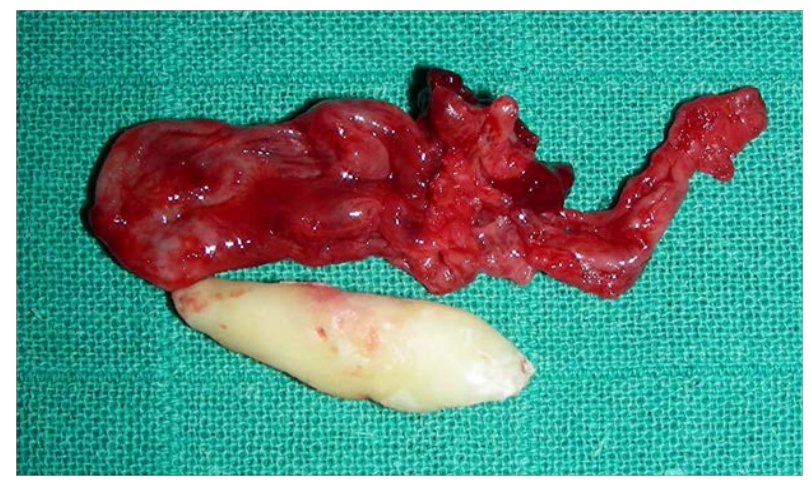

Figure 5. Operatory biopsy with the impacted root tooth.

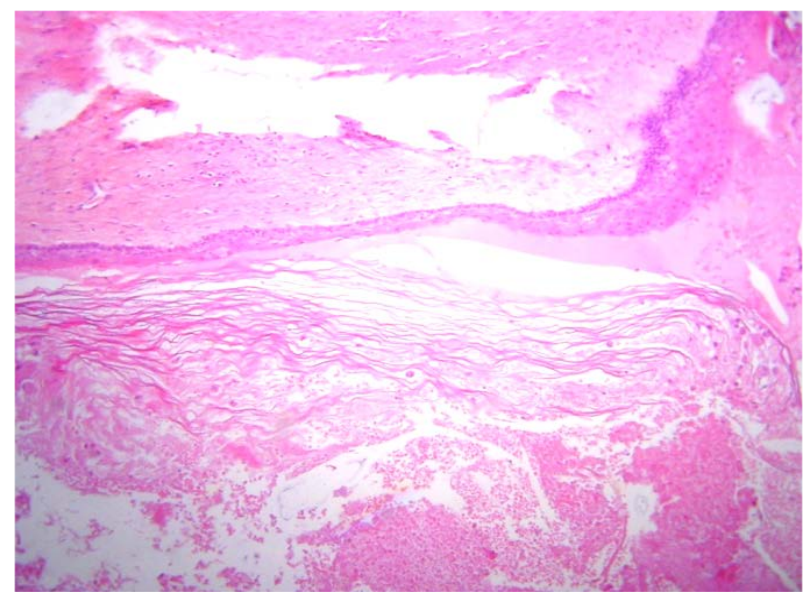

Figure 6. Histological section: cyst wall lined by stratified squamous epithelium and the corrugated parakeratinized surface (Hematoxylin and eosin stain, $\mathrm{G} \times 40$ ). 


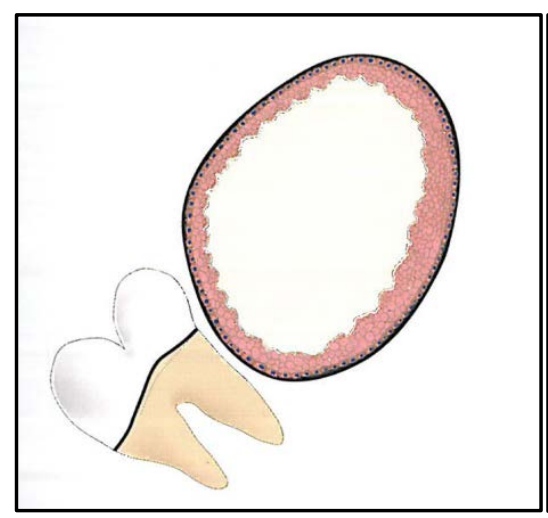

(a)

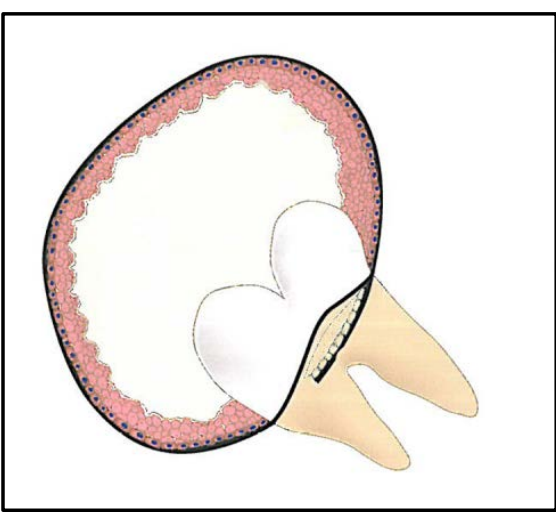

(b)

Figure 7. (a) Primordial-origin odontogenic keratocysts; (b) Dentigerous-origin.

Keratocystic odontogenic tumors may occur at virtually any age, but the highest incidence is generally in the second and third decades of life [2] [3] [9] [10]. Several authors have also noted a second peak between the fifth and eighth decades [9]. Chow [12], Brannon [13] and Browne [3] found a mean age of 32.1 - 37.8 years at time of diagnosis. The age distribution appears to be bimodal [9]. The sex distribution may be equal, or may be a male predominance (1.3 - 3.1) [9].

KCOTs may occur in any part of the upper and lower jaw, cysts of the jaws, with the majority occurring in the mandible, most commonly in the angle of the mandible and ramus [9] [10]. The KCOT involves approximately $11 \%$ of all cysts in the jaws and is most often located in the mandibular ramus and angle. However, our patient had a relatively rare localization in the maxilla. This lesion can be associated, although not in all cases, with an impacted tooth [14] and most frequently located within the jaws. Nevertheless, some rare cases have occurred in the gingiva. This form has been designated as peripheral odontogenic keratocyst. Such lesions are often misdiagnosed as gingival cyst of the adult, or lateral periodontal cyst or lateral radicular cyst. Peripheral odontogenic keratocyst is clinically aggressive and has the potential to recur as the classical odontogenic keratocyst [15].

The odontogenic keratocyst is an important part in the clinical features of basal cell nevus syndrome or Gorlin and Goltz syndrome. Mutation of the PTCH gene is partly responsible; the partial expression may be at the origin of the appearance of multiple recurrent keratocysts.

The basal cell nevus syndrome (also called Gorlin syndrome or Gorlin-Goltz syndrome) is a genetic condition with an autosomal-dominant inheritance pattern that includes a triad of multiple KCOTs of the jaws, other skeletal abnormalities (often including bifid ribs, abnormalities in the length of the fingers and toes, frontal bossing, and calcification of the falx cerebri), as well as cutaneous manifestations such as basal cell carcinomas, palmar pitting of the hands, and other skin abnormalities [16] [17]. Renal abnormalities and medulloblastomas in the newborn may also be manifestations of this condition. Whether sporadic or hereditary, most cases are related genetically and show aberrations in the hedgehog signaling pathway.

The hedgehog signaling pathway involves a dynamic relationship between a series of tumor suppressor genes and oncogenes [5].

Most keratocysts are asymptomatic. Inflammation, pain, discomfort or a spontaneous endobuccal flow fistu-lation are possible. In the most aggressive forms [18] expansion of the buccal and lingual plates occurs late with this lesion (in contrast to the ameloblastoma), because it primarily tends to invade the marrow. However, it does cause some expansion of the lingual plate and can cause lingual plate perforation. Inferior alveolar nerve involvement occurs late [5].

Radiographically, KCOTs demonstrate a well-defined unilocular or multilocular radiolucency with smooth and often corticated margins. KCOTs tend to grow in an anteroposterior direction within the medullary cavity of the bone and may cause an obvious bone expansion [5] [9] [10] [18].

Displacement of teeth adjacent to the cyst occurs more frequently than resorption [9] [14].

The lesion may be single or multiple, the latter case being more common in patients with the Gorlin and Goltz syndrome. The KCOTs must be differentiated from the ameloblastoma, since both lesions may appear as unilocular or multilocular radiolucencies and may cause external resorption of the teeth and expansion of the bone [19] [20], 
furthermore, they both occur in the same age range and demonstrate a predilection for the posterior mandible and a high recurrence rate [9]. Other cyst and neoplstic diseases, such as dentigerous cyst, traumatic bone cyst, minimally calcifying odontogenic cyst, central giant cell granuloma, and ameloblastic fibroma, can present with the same radiologic features [21].

These tumors are normally diagnosed histologically from a sample of the lining. This diagnosis requires a surgical biopsy, and difficulties can arise when the cyst has been previously exposed or inflamed, when the lining tends to become thicker and less obviously parakeratinized. Diagnose is normally made on permanent paraffinstained sections, although attempts have been made to diagnosis it from frozen section so that definitive treatment can be performed at the same time as the biopsy [5] [22]. KCOT has a stratified epithelium lining, typically thin and uniform thickness free of inflammation, and with corrugated parakeratinized. The basal layer of the lesion is well defined cuboidal or columnar cells with palisading [23].

The main goal of all surgeons is to eradicate the lesion with whatever means that might be applicable to the particular lesion according to the site, size and location. There are pros and cons for all the treatment options. A variety of treatment modalities, ranging from conservative to radical, have been developed in an attempt to definitively treat KCOT [24]. The general approach to treating KCOT is enucleation and curettage, and the alternative therapies of decompression/marsupialization are also valid but have specific limited indication [10].

Most clinicians favor "conservative” therapy, while others advocate more "aggressive” forms of treatment. Meiselman et al. consider "enucleation, curettage and marsupialization” as conservative therapies [20]. Williams et al. defined aggressive treatment as "that which is used in addition to enucleation and includes curettage (mechanical, and/or chemical) and/or resection without loss of jaw continuity” [25]. Morgan et al. also categorize treatment methods for KCOT as conservative or aggressive, both being forms of surgical intervention [26]. Aggressive treatment addresses the "neoplastic nature” of KCOT and includes peripheral ostectomy, chemical curettage with Carnoy's solution or en bloc/segmental resection. Excision of the mucosa overlying the lesion has been recommended, based on histological evidence that clusters of epithelial islands and microcysts (presumably with the potential to cause recurrence), found in the area where the lesion was connected with the mucosa [24].

The terms decompression and marsupialization are used interchangeably; however, they are conceptually different, decompression tech-nically denotes any treatment whereby the pressure is taken off the tumor by creation of a hole in the tumor from which it can drain. This can be a small opening into which a decompression tube can be placed. Decompression is normally used as a means of decreasing the size of a KCOT so that it can be enucleated later without risking additional teeth, the inferior alveolar nerve, or the integrity of the mandible [27] [28].

Marsupialization is a form of decompression that denotes the creation of a wider opening, which is often self-sustaining, and this treatment can be performed for complete cure of the lesion. Although KCOT is an aggressive tumor, it does appear to respond successfully to marsupialization and can resolve totally following marsupialization, often over a period of 6 to 12 months. Histologic examination has shown that as the marsupialized tumor decreases in size, the lining differentiates from the typical appearance of a KCOT to one more closely resembling oral mucosa. Whether this occurs by metaplasia or overgrowth from the periphery remains unclear [27]. However, decompression or marsupialization has not been recommended alone for the treament of keratocyst, as such reports have documented recurrence rates between $0 \%$ and $100 \%$ [7].

Enucleation is another form of cyst treatment. Given the recurrence rate to be as high as $62.5 \%$, simple enucleation is no longer acceptable. Curettage and enucleation are considered by many as minimal requirement, therapeutically. Therefore, in order to make these more effective, Stoelinga advocated excising the overlying oral mucosa in continuity with the cystic lesion [29] [30]. However, many authors have cited difficulty in enucleation and curettage of KCOT with or without cortical perforation, as adherence of the thin friable lining to adjacent bone or soft tissue may preclude complete enucleation [30] [31]. With the additional application of CS, a recurrence rate between $1 \%$ and $8.7 \%$ is observed [30] [32]. But curettage or peripheral ostectomy after enucleation does not lower recurrence rates, as compared to enucleation alone [2].

Aggressive surgery/resection is indicated in multiple recurrences, in tumors that cannot be managed by other methods, and in malignant transformation since cases of carcinoma arising from KCOT have been documented [10] [24]. Conversely, cases have been successfully treated by marsupialization alone, and this, in consequence, would deny KCOT of its tumorigenic nature. In fact, a lesion has also been reported to recur in a bone graft [33]. According to literature, radical excision has no recurrence, i.e. 0\%, but is associated with high morbidity and therefore should be reserved only after initial intervention has failed. In view of the cyst size and degree of osteolysis, aggressive resection may well be indicated in our case, but conservative therapy seemed to generate an 
excellent response.

The reasons for this recurrence rate are believed to be 3-fold [5] [28]:

- They have a thin lining, which is friable, and portions are easily left behind.

- Daughter cysts occur beyond the visible margin of the lesion.

- Some of these lesions may originate from the oral mucosa and daughter cysts are seen between the oral mucosa and the cyst itself. Unless these lesions are removed, recurrence is likely.

Post-operative follow-up with annual radiological examinations is essential for at least five years following surgery. Recurrence is documented even after 10 years of follow-up and treatment. However, it is difficult to diagnose recurrence with regard to cysts in the maxillary sinus after the surgical removal of the initial lesion. Therefore CT is important in assessing the full extent of the recurrent lesion preoperatively [9].

\section{Conclusion}

The recommended follow up for KCOTs is once in a year for at least 5 years. Radical operations, such as continuity resection may not be warranted always, as conservative management with marsupialization seems to work and preserves function with least morbidity. Many authors are now advocating a more conservative approach in treating the single non syndromic odontogenic keratocyst. Recurring KCOTs will require a more radical surgery. Radical procedures such as resection should be reserved for keratocysts that involve vital structures, are recurrent or demonstrate malignant degeneration.

\section{References}

[1] Philipsen, H.P. (1956) OM Keratocyster (Kolesten-Tomer). Tandialgebladet, 60, 963. (In Danish)

[2] Browne, R.M. (1970) The Odontogenic Keratocyst. Clinical Aspects. British Dental Journal, 128, 225. http://dx.doi.org/10.1038/sj.bdj.4802449

[3] Browne, R.M. (1971) The Odontogenic Keratocyst. Histological Features and Their Correlation with Clinical Behaviour. British Dental Journal, 131, 249. http://dx.doi.org/10.1038/sj.bdj.4802732

[4] Partridge, M. and Towers, J.F. (1987) The Primordial Cyst (Odontogenic Keratocyst): Its Tumour-Like Characteristics and Behaviour. British Journal of Oral and Maxillofacial Surgery, 25, 271. http://dx.doi.org/10.1016/0266-4356(87)90065-9

[5] Pogrel, M.A. (2013) The Keratocystic Odontogenic Tumor. Oral \& Maxillofacial Surgery Clinics of North America, 25, 21-30. http://dx.doi.org/10.1016/j.coms.2012.11.003

[6] Shear, M. (2002) The Aggressive Nature of the Odontogenic Keratocyst; Is It a Benign Cystic Neoplasm? Part 1. Clinical and Early Experimental Evidence of Aggressive Behavior. Part 2. Proliferation and Genetic Studies. Part 3. Immunocytochemistry of Cytokeratin and Other Epithelial Cell Markers. Oral Oncology, 38, 219-226, 323-331, 407-415. http://dx.doi.org/10.1016/S1368-8375(01)00065-3

[7] Barreto, D.C., Gomez, R.S., Bale, A.E., Boson, W.L. and De Marco, L. (2000) PTCH Gene Mutations in Odontogenic Keratocysts. Journal of Dental Research, 79, 1418-1422. http://dx.doi.org/10.1177/00220345000790061101

[8] Praetorius, F. and Ledesma-Montes, C. (2005) Dentinogenic Ghost Cell Tumour. In: Barnes, L., Eveson, J.W., Reichart, P. and Sidansky, D., Eds., World Health Organization Classification of Tumor. Pathology and Genetics of Head and Neck Tumours. IARC Press, Lyon, 314.

[9] Yang, S., Park, Y.-I., Choi, S.-Y., Kim, J.-W. and Kim, C.-S. (2011) A Retrospective Study of 220 Cases of Keratocystic Odontogenic Tumor (KCOT) in 181 Patients. Asian Journal of Oral and Maxillofacial Surgery, 23, 117-121. http://dx.doi.org/10.1016/j.ajoms.2011.03.002

[10] Marx and Stern (2012) Oralvand Maxillofacial Pathology: A Rational for Diagnosis and Treatment. 2nd Edition, 616631.

[11] Shuster, A., Shlomi, B., Reiser, V. and Kaplan, I. (2012) Solid Keratocystic Odontogenic Tumor-Report of a Nonaggressive Case. Journal of Oral and Maxillofacial Surgery, 70, 865-870. http://dx.doi.org/10.1016/j.joms.2011.02.140

[12] Chow, H.T. (1998) Odontogenic Keratocyst: A Clinical Experience in Singapore. Oral Surgery, Oral Medicine, Oral Pathology, Oral Radiology, and Endodontology, 86, 573-577. http://dx.doi.org/10.1016/S1079-2104(98)90348-1

[13] Brannon, R.B. (1976) The Odontogenic Keratocyst; a Clinicopathologic Study of 312 Cases. Part I. Clinical Features. Oral Surgery, 42, 54-72. http://dx.doi.org/10.1016/0030-4220(76)90031-1

[14] Ebenezer, V., Balakrishnan, B. and Sivakumar, M. (2014) A Case Report on Surgical Management of Odontogenic 
Keratocyst. World Journal of Medical Sciences, 10, 212-216.

[15] Schaer, M. and Lombardi, T. (2013) Kératokyste odontogène périphérique: Rappel embryologique et revue de littérature. Médecine Buccale Chirurgie Buccale, 19, 101-108. http://dx.doi.org/10.1051/mbcb/2013061

[16] Scully, C., Langdon, J. and Evans, J. (2010) Marathon of Eponyms: 7 Gorlin-Goltz Syndrome (Naevoid Basal Cell Carcinoma Syndrome). Oral Diseases, 16, 117-118. http://dx.doi.org/10.1111/j.1601-0825.2009.01539.x

[17] Todd, R. and August, M. (2003) Molecular Approaches to the Diagnosis of Sporadic and Naevoid Basal Cell Carcinoma Syndrome-Associated Odontogenic Keratocysts. Oral and Maxillofacial Surgery Clinics of North America, 15, 447-461. http://dx.doi.org/10.1016/S1042-3699(03)00039-6

[18] Ruhin-Poncet, B., Picard, A., Martin-Duverneuil, N., Albertini, A.-F. and Goudot, P. (2011) Kératokystes ou tumeurs odontogéniques kératokystiques. Revue de Stomatologie et de Chirurgie Maxillo-faciale, 112, 87-92. http://dx.doi.org/10.1016/j.stomax.2011.01.010

[19] Henley, J., Summerlin, D.J., Tomich, C., Zhanq, S. and Chenq, L. (2005) Molecular Evidence Supporting the Neoplastic Nature of Odontogenic Keratocyst: A Laser Capture Microdissection Study of 15 Cases. Histopathology, 47, 582-586. http://dx.doi.org/10.1111/j.1365-2559.2005.02267.x

[20] Meiselman, F. (1994) Surgical Management of the Odontogenic Keratocyst: Conservative Approach. Journal of Oral and Maxillofacial Surgery, 52, 960-963. http://dx.doi.org/10.1016/S0278-2391(10)80080-1

[21] Giuliani, M., Grossi, G.B. and Lajolo, C. (2006) Conservative Management of a Large Odontogenic Keratocyst; Report of a Case and Review of Literature. Journal of Oral and Maxillofacial Surgery, 64, 308-316. http://dx.doi.org/10.1016/j.joms.2005.10.013

[22] Guthrie, D., Peacock, Z.S., Sadow, P., Dodson, T.B. and August, M. (2012) Preoperative Incisional and Intraoperative Frozen Section Biopsy Techniques Have Comparable Accuracy in the Diagnosis of Benign Intraosseous Jaw Pathology. Journal of Oral and Maxillofacial Surgery, 70, 2566-2572. http://dx.doi.org/10.1016/j.joms.2011.11.023

[23] Jardim, E.-C.-G., Rossi, A.-C., Faverani, L.-P., Ferreira, G.-R., Ferreira, M.-B., Vicentes, L.-M. and Jonior, I.-G.-R. (2013) Odontogenic Keratocyst Tumor: Report of Two Cases. International Journal of Odontostomatology, 7, 33-38.

[24] Bharani, K.S.N.S., Lakshmi, S.S., Kamath, A.D.R. and Hammannavar, R. (2013) Keratocystic Odontogenic Tumor: Case Report, Treatment Review and Future Diagnostic Trends. Journal of Oral and Maxillofacial Surgery, Medicine, and Pathology, 25, 85-92. http://dx.doi.org/10.1016/j.ajoms.2012.01.011

[25] Williams, T.P. and Connor, F.A. (1994) Surgical Management of the Odontogenic Keratocyst. Journal of Oral and Maxillofacial Surgery, 52, 964-966. http://dx.doi.org/10.1016/S0278-2391(10)80081-3

[26] Morgan, T.A., Burton, C.C. and Quian, F. (2005) A Retrospective Review of Treatment of the Odontogenic Keratocyst. Journal of Oral and Maxillofacial Surgery, 63, 635-639. http://dx.doi.org/10.1016/j.joms.2004.07.026

[27] Porgel, M.A. (2012) Keratocystic Odontogenic Tumor. Current Therapy in Oral and Maxillofacial Surgery, 271-274.

[28] Baaroun, V., Toledo, R., Azerad, J. and Descroix, V. (2014) Tumeur kératokystique étendue: A propos d'un cas. Médecine Buccale Chirurgie Buccale, 20, 47-51. http://dx.doi.org/10.1051/mbcb/2013092

[29] Stoelinga, P.J.W. (2003) Excision of the Overlying, Attached Mucosa, in Conjunction with Cyst Enucleation and Treatment of the Bony Defect with Carnoy's Solution. The Odontogenic Keratocyst. Oral and Maxillofacial Surgery Clinics of North America, 15, 407-414. http://dx.doi.org/10.1016/S1042-3699(03)00033-5

[30] Kaczmarzyk, T., Mojsa, I. and Stypulkowska, J. (2012) A Systematic Review of the Recurrence Rate for Keratocystic Odontogenic Tumour in Relation to Treatment Modalities. International Journal of Oral and Maxillofacial Surgery, 41, 756-767. http://dx.doi.org/10.1016/j.ijom.2012.02.008

[31] Fickling, B.W. (1965) Cysts of the Jaw: A Long-Term Survey of Types and Treatment. Proceedings of the Royal Society of Medicine, 58, 847-854.

[32] Blanas, N., Freund, B., Schwartz, M. and Furst, M. (2000) Systematic Review of the Treatment and Prognosis of the Odontogenic Keratocyst. Oral Surgery, Oral Medicine, Oral Pathology, Oral Radiology, and Endodontology, 90, 553558. http://dx.doi.org/10.1067/moe.2000.110814

[33] DeGould, M.D. and Goldberg, J.S. (1991) Recurrence of an Odontogenic Keratocyst in a Bone Graft. International Journal of Oral Surgery, 20, 9-11. http://dx.doi.org/10.1016/S0901-5027(05)80686-1 


\section{Submit or recommend next manuscript to SCIRP and we will provide best service for you:}

Accepting pre-submission inquiries through Email, Facebook, LinkedIn, Twitter, etc.

A wide selection of journals (inclusive of 9 subjects, more than 200 journals)

Providing 24-hour high-quality service

User-friendly online submission system

Fair and swift peer-review system

Efficient typesetting and proofreading procedure

Display of the result of downloads and visits, as well as the number of cited articles

Maximum dissemination of your research work

Submit your manuscript at: http://papersubmission.scirp.org/ 